International Review of Research in Open and Distributed Learning Volume 17, Number 3

April - 2016

\title{
Instructor's Use of Social Presence, Teaching Presence, and Attitudinal Dissonance: A Case Study of an Attitudinal Change MOOC
}
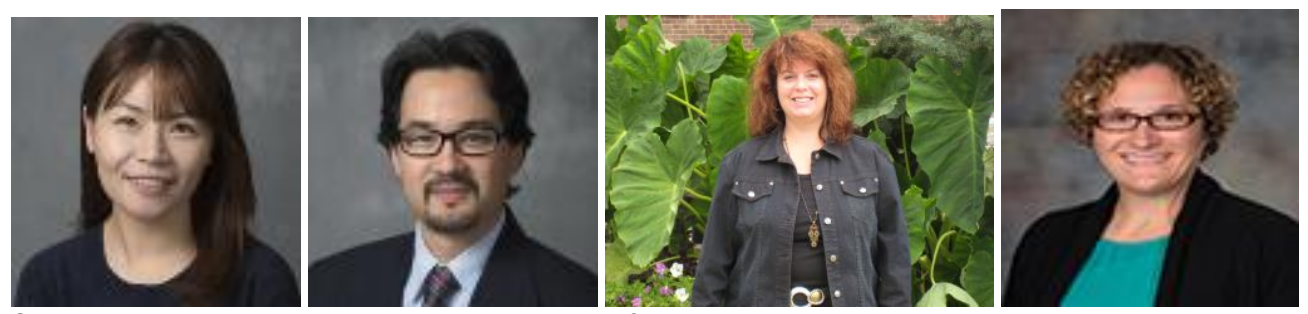

Sunnie Lee Watson, William R. Watson, Jennifer Richardson, and Jamie Loizzo

Purdue University, University of Nebraska-Lincoln

\begin{abstract}
This study examines a MOOC instructor's use of social presence, teaching presence, and dissonance for attitudinal change in a MOOC on Human Trafficking, designed to promote attitudinal change.

Researchers explored the MOOC instructor's use of social presence and teaching presence, using the Community of Inquiry (CoI) framework as a lens, and examined the facilitation of attitudinal dissonance within the discussion forum, announcements and blog postings in the course. The instructor entered the MOOC with the idea of serving as a co-participant and a facilitation choice was made to address the issue of multiple perspectives and experiences. The instructional design focused on establishing a collaborative community of learners and this was demonstrated through a high number of social presence indicators but with significant use of all three areas in evidence. Findings present a detailed examination of instructor strategies in a MOOC designed to focus on the establishment of a collaborative learning community and can inform future instructional design and instruction of MOOCs in general and MOOCs for attitudinal change specifically.
\end{abstract}

Keywords: social presence, teaching presence, attitude change, MOOC

\section{Introduction}

Massive Open Online Courses (MOOCs) have gained attention as an innovative approach to leveraging technology for higher education instruction. Labeled as a potentially disruptive innovation to higher education (Flynn, 2013; Carver \& Harrison, 2013), MOOCs present free online courses; although increasingly, students can pay to earn an official certificate of completion. With a goal of making access to 
higher education available to a global audience (Liyanagunawardena, Adams, \& Williams, 2013), MOOCs have enrollment counted in the tens-of-thousands. The global and massive nature of the typical student body allows for interaction amongst participants unlike any other course offering, supporting the democratization of higher education (Carver \& Harrison, 2013). This makes MOOCs uniquely situated to educational outreach, and in particular, education focused on attitudinal and social change through discussion and discourse.

While MOOCs initially were offered in the hard sciences and computer programming, courses have become increasingly diverse with offerings in the social sciences, including those with targeted attitudinal outcomes, such as Ethics of Eating, Science of Happiness, and Animal Behavior and Welfare MOOCs. Despite the common inclusion of attitudinal change as a goal in various disciplines such as health or citizenship education, the literature around effective facilitation practices for attitudinal change is limited. Likewise, limited studies focus on MOOC instructors' facilitation strategies (Liyanagunawardena et al., 2013, Watson, Kim, \& Watson; 2016). This study examines an instructor's use of social presence, teaching presence and dissonance within a MOOC for attitudinal change, providing implications for effective facilitation approaches to attitudinal change and MOOCs.

\section{Literature Review}

\section{Social Presence and Teaching Presence}

The Community of Inquiry (CoI) framework is a process model for online learning environments that focuses on collaborative constructivist learning environments (Garrison, Anderson \& Archer, 2000) that has been utilized by many researchers to examine online instructional environments. The CoI framework analyzes online instructional environments through the interaction of three components: social presence (SP), teaching presence (TP), and cognitive presence (CP; Garrison, 2007). SP is the degree to which participants identify with and feel connected to each other in an online environment (Garrison, 2011). TP refers to the methods that an instructor utilizes to promote a quality online environment and facilitate an effective CoI (Bangert, 2008). Finally, CP refers to students' process of constructing meaning through discourse and reflection (Garrison, Anderson, \& Archer, 2001). The interaction of these three components creates the online collaborative constructivist experience and is helpful in describing this experience. For the purpose of this study we will be focusing on SP and TP.

Garrison (2012) discusses the misapplication of the CoI to all online environments, even ones where little interaction between participants or discourse exist. Traditional MOOCs and AI-Stanford MOOCs (xMOOCs), like many in the computer and hard sciences, offer little interaction between participants, instead relying on independent student work, automated feedback in the form of quizzes, and instructor provided lecture videos and resources (Rodriguez, 2012). However, in a MOOC designed to promote attitude change, such as the one analyzed in this study, interaction is key to meeting attitudinal learning outcomes, and therefore, makes the CoI framework relevant for analyzing interactions.

Garrison et al. (2000) argue that SP, or student interaction with peers, is necessary to ensure an effective online learning environment. The definition of SP has evolved over time but at the core it is "the degree to 
which participants in computer-mediated communication feel affectively connected one to another" (Swan, Garrison, \& Richardson, 2009, p. 47). SP is comprised of three elements: affective expression, open communication, and group cohesion (Swan et al. 2009). Affective expression refers to the sharing of personal beliefs, values and attitudes; open communication focuses on building a sense of group commitment; and group cohesion refers to learners focusing on common intellectual tasks (Swan et al., 2008). It is possible that SP based on these elements may be more challenging to achieve, given the massive numbers of participants in a MOOC thereby providing less opportunity to connect at a personal level. However, learner perceptions of SP have been found to be predictive of perceived learning outcomes in traditional online courses (Hostetter \& Busch, 2013; Picciano, 2002; Richardson \& Swan, 2003; Russo \& Benson, 2005) as well as learners' satisfaction with the course and instructor (Gunawardena, 1995; Hostetter \& Busch, 2006; Richardson \& Swan, 2003). Researchers recommend the inclusion of social aspects of learning in the design of online courses (Mykota \& Duncan, 2007; Swan, Matthews, Bogle, Boles \& Day, 2012; Tu, 2002; Wei, Chen, \& Kinshuk, 2012), and SP may play an important role in effective attitudinal change instruction.

Teaching Presence (TP), which Garrison et al. (2000) call the binding element, is composed of design and organization, facilitating discourse, and direct instruction (Swan et al., 2008). Instructional course design describes the planning and design of the course structure and process, including the interaction and evaluation; facilitating discourse refers to reviewing and commenting on student discussion, asking questions, and managing the discussion; and, direct instruction describes the instructor as subject matter expert, providing leadership through the sharing of expertise (Anderson, Rourke, Garrison, \& Archer, 2001). Research on TP has shown it to impact students' perceptions of higher levels of learning (Morris, 2011; Kanuka, 2011; Shea, Li, \& Pickett, 2006) and their success in online courses (Arbaugh, 2010; Garrison, Cleveland-Innes, \& Fung, 2010; Kupczynski, Ice, Wiesenmayer, \& McCluskey, 2010). While there is a considerable difference in size, Nagel and Kotze (2010) have shown that larger classes ( $\mathrm{n}=186)$ can employ techniques such as peer review and content and process scaffolds as a means to nurture student perceptions of high levels of teaching, social, and cognitive presence, and this provides us with insights for the design of MOOCs. This study also highlights the fact that TP is not just about the teacher; peers can also take on part of that presence. Ultimately, we need to reflect on the foundation of the CoI framework and the collaborative-constructivist view it is based on: people learn from their environments and each other; therefore, collaborative environments that respect individual learning support students in assuming responsibility to actively construct and confirm meaning (Swan, Garrison \& Richardson, 2009).

\section{Dissonance for Attitude Change}

While various definitions for attitude are offered (Simonson \& Maushak, 1996), it is largely accepted that attitudes represent the psychological evaluations an individual holds regarding another person, object, or event (Gagne, Briggs \& Wagner, 1992; Zimbardo \& Leippe, 1991). Furthermore, attitude is comprised of three components: affective-evaluation based on emotion; cognitive-evaluation based on knowledge or thoughts; and, behavioral-an individual's actual actions taken towards a person, object, or event (Kamradt \& Kamradt, 1999; Simonson, 1979). 
Although it can be difficult to draw distinctions between which component is targeted in attitudinal instructional approaches due to the frequency with which components overlap (Kamradt \& Kamradt, 1999), instructional strategies largely align with an attempt to create a form of dissonance, which can be understood as a tension or clash within an individual's attitudinal components. For example, for an individual who has knowledge of a social problem and is emotionally affected by concrete examples or narratives related to the problem, yet takes no action to solve or address the problem, dissonance may exist between the person's affect (feeling) and cognition (knowledge) and her behavior (action or lack of action in this case). Instructional strategies targeting attitude may seek to stimulate this dissonance in order to move the student to better align the state of the three components comprising her attitude.

Therefore, strategies targeting the affective component create dissonance by provoking an emotional reaction from the student (Kamradt \& Kamradt, 1999; Simonson, 1979), such as the use of rich media to evoke an emotional response and shift learner attitudes in a targeted direction (Simonson \& Maushak, 1996). Instructional strategies targeting the cognitive component create dissonance by presenting new information that helps establish a receptive mind which has been found to be critical in changing attitude (Bodenhausen \& Gawronski, 2013). Strategies targeting the behavioral component create dissonance by asking learners to perform an act aligned with the desired attitude; something they will do readily if their attitude is already close to the desired attitude, refuse to do if their attitude is too far away from the desired state, and do somewhat uncomfortably if the instruction is ideal to shift them significantly towards the desired attitude (Kamradt \& Kamradt, 1999). As Kamradt and Kamradt explain, the "most reliable instructional strategy is to ask the learner to perform some action that is slightly inconsistent with their existing attitude and [in] the direction of being consistent with the target attitude" (p. 587). Given the overlap that can occur between components, the design of strategies across affective, cognitive, and behavioral areas may best create and enhance learner dissonance, resulting in attitudinal change.

\section{Effective MOOC Facilitators}

Early MOOCs were based on a connectivist framework, described as c-MOOCs (Liyanagunawardena et al., 2013). c-MOOCs focus on student-driven social networking approaches to learning and have been criticized for their lack of instructor presence and reliance on students to make sense of materials (Clarà \& Barberà, 2013). In contrast, recent MOOC offerings have been more instructor-driven and structured, providing a self-paced learning environment that requires less learner interaction and are described as AIStanford or xMOOCs (Rodriguez, 2012).

While Ross, Sinclair, Knox, Bayne, and Macleod (2014) call for further research on the complexities of instructor roles in MOOCs, they describe three traditional MOOC instructor roles: 'the distant 'rock star' lecturer, the co-participant or facilitator within a network, and the automated processes that serve as proxy tutor and assessor" (p. 58). In xMOOCs, the role of the facilitator is critical, given the instructordriven nature of the course, and yet also challenging given the massive numbers of students and their diverse background and goals. 
Social discussion can be an effective way to help attitude change. Seeing how one's attitude is aligned to a perceived social consensus regarding the topic can enhance confidence about newly established attitudes (Petrocelli, Tormala, \& Rucker, 2007). Effectively structuring and facilitating an instructional environment for attitudinal change that encourages collaboration and critique has been found to be effective (Kamradt \& Kamradt, 1999; Simonson \& Maushak, 1996). Encouraging learners to publicly demonstrate their new attitudes builds off other collaborative activities to increase confidence in the new attitude (Kamradt \& Kamradt, 1999; Simonson, 1979; Simonson \& Maushak, 1996).

This study examines a MOOC designed to promote attitudinal change where the instructor sought to serve as a co-participant or facilitator, and where discussion and establishment of a community of activists were identified as the core instructional strategies. The study's intent was to examine the instructor's use of SP, $\mathrm{TP}$, and dissonance for attitudinal change.

\section{Methods}

\section{Research Design}

A qualitative interpretive research design was applied to explore how a MOOC instructor facilitated a MOOC for attitudinal change on the topic of human trafficking (HT). Specifically, the researchers explored the instructor's use of SP and TP, using the CoI framework as a lens, and examined the facilitation of dissonance within the discussion forum, announcements and blog postings in the course. The research questions included:

1. How did a MOOC instructor establish social presence to facilitate attitude change around the social issue of HT?

2. How did a MOOC instructor establish teaching presence to facilitate attitude change around the social issue of HT?

3. How did a MOOC instructor establish cognitive, affective and behavioral dissonance to facilitate attitude change around the social issue of HT?

\section{Description of the Course and Setting}

The title of the MOOC was Human Trafficking. According to the syllabus, the course goals were:

Dialogue and action are the goals... sharing of ideas related to increased awareness, prevention, detection, research, law enforcement, rescue, and restoration is sure to result in tangible and concrete ideas that will advance the anti-trafficking movement in many parts of the world. 
The United Nations General Assembly (2000) describes HT as recruiting, transporting, harboring, or receiving persons through deceptive measures and exploiting them for various purposes such as labor, slavery, and sexual acts. The course was offered in the fall of 2014 through a leading MOOC platform, Coursera, with a faculty instructor at a large Midwestern public university. The MOOC offered weekly lecture videos and resource videos, readings, quizzes, discussions, and a public service announcement (PSA) project assignment. The instructor designed the course in collaboration with a senior instructional designer to change attitudes and motivate learners to be activists in fighting HT in their communities. The facilitation model employed in this MOOC saw the instructor lead the content instruction and discussion facilitation, and the instructional designer lead the course organization tasks, such as assignment reminders and answering course navigation, and technology questions, serving a teaching assistant role.

The MOOC ran for four weeks and had 30,207 registered learners from 186 countries. There was a wide range of attitudes along the anti-trafficking attitude continuum, from learners who were unaware of HT and its existence in their communities to those who were already working with anti-trafficking organizations to fight HT, according to the self-introductions posted by the learners. At the end of the course, 1,253 students completed the MOOC and received a statement of accomplishment.

The instructor was an African American female in a tenured associate professor position in the College of Social Work at the Midwestern University. She held a license in social work, had conducted international HT research, and had years of experience teaching undergraduate and graduate students. She had been teaching a face-to-face HT course, and this was the first time she taught the course in an online environment, as well as her first time teaching a MOOC.

\section{Data Collection}

The primary source of data were the online discussion posts, which we captured within the MOOC discussion forums. There were 128 posts by the instructor. We also reviewed the instructor's 12 announcements and one blog post. Finally, we conducted a sixty-minute interview session with the instructor through Skype. The instructor was asked about her experiences, intentions, and perspectives on facilitating the course. Semi-structured, open-ended questions were asked for an in-depth understanding of her facilitation experiences. The interview was video recorded and transcribed verbatim. In addition, we reviewed the course syllabus, videos, and resources.

\section{Data Analysis}

A group of four researchers worked collaboratively on the data analysis. Overall, 143 posts were coded, including the instructor's discussion posts, announcements, and blog posts. We used an interpretive, qualitative approach, with content analysis of discussion postings, to address the research questions.

The qualities of instructor facilitation strategies in the posts were coded and categorized into three areas: the use of SP, TP, and attitudinal dissonance, which include cognitive, affective and behavioral dissonance strategies (see Appendix). Both inductive and deductive methods were used to develop the coding schema. First, codes were taken from previous relevant literature (Richardson et al., 2015). At the same time, 
guided by the definitions of SP, TP, and dissonance for attitude change, additional codes emerged from the discussions during initial data analysis (see Appendix). The posts were analyzed using a constant comparison method (Glaser, 1965), to identify key themes related to strategies the instructor used to facilitate the MOOC and discussions. It is important to note that traditionally TP codes include a set that are categorized as design and organization codes (e.g. reminders, navigation, technology, and design methods). However, in the case of this MOOC, these activities were handled by the instructional designer and not the instructor and as such were not included in the analysis.

Discussion posts were analyzed using a constant comparison method (Glaser, 1965), to identify key themes related to strategies the instructor used to facilitate the MOOC and discussions. Posts were coded at the sentence level and had a variety of representations. For example, this included descriptive sentences of how to approach an assignment in order to create a real world application of the learning as well as such simple responses as providing a due date. Reliability was established in the coding procedure as three researchers independently coded instructors' postings allowing for triangulation of coding. Results were then compared and consensus building allowed for 100\% inter-coder agreement (Creswell, 2014).

Interview data were also analyzed for a deeper understanding of more holistic and broad intentions of the facilitation. The interview focused on the instructor's utilization of facilitation strategies to improve student learning. Interview transcription was reviewed to identify the big picture regarding facilitation. Then all data were divided into meaningful units and compared with the results of the coded discussion posts, announcements, and blog post. Next, we engaged in structural analysis to formulate meaningful themes.

Meaningful themes were crosschecked across data sources (e.g., discussion and announcement posts, interview data and course artifacts), and discussed and revised until consensus was reached across researchers. We then reviewed the data through the initial focus of the study by reflecting on the research questions and themes. Finally, member-checking was applied, sharing the final analysis with the participant for approval.

\section{Results}

The 143 instructor posts included 128 from the discussion forums, 12 announcements, and one blog post. The discussion posts were from Weekly Forums that consisted of discussion prompts, the Share Your Story forum, and forums that were created for sharing course assignments. The announcements consisted of a welcome message, weekly announcements and announcements regarding assignments. The blog post was the instructor's first course post to the learners that invited them to learn about HT and work to find anti-HT solutions.

Table 1

Social, Teaching and Dissonance Codes 
Instructor's Use of Social Presence, Teaching Presence, and Attitudinal Dissonance: A Case Study of an Attitudinal Change MOOC Watson, Watson, Richardson, and Loizzo

\begin{tabular}{llll}
\hline Total coding references & No. (\%) SP codes & No. (\%) TP codes & $\begin{array}{l}\text { No. (\%) dissonance } \\
\text { codes }\end{array}$ \\
\hline 1,248 & $541(43 \%)$ & $411(33 \%)$ & $296(24 \%)$ \\
\hline
\end{tabular}

The codes used for analyzing the posts were based on SP, TP, and the creation of dissonance. A total of 1,248 coding references were found within the 143 posts, with the highest percentage demonstrating SP (Table 1). However, significant use of all three areas was in evidence, as demonstrated by a code from each of the three areas under investigation being utilized in the top five codes (Table 4). With the top code of clarify, we see the instructor's role as a teacher, helping students successfully navigate the MOOC. Likewise, the presence of four SP codes in the top 10 demonstrates the instructors' consistent and varied efforts to establish her SP within the course (Table 2). Of course, some codes, like greeting and name require less effort on the part of the instructor than repeating or acknowledging student posts.

Nevertheless, together the SP codes show a strong effort by the instructor to have a presence in the forums and facilitate a sense of her SP in the course. Finally, with two dissonance codes in the top five and three in the top seven, the codes relate the strong efforts to introduce dissonance in regards to the topic. We provide a detailed description of the instructor's strategies in establishing SP, TP, and dissonance in the next sections.

Table 2

Top 10 Instructor Post Codes

\begin{tabular}{lc}
\hline Code rank and name & Observations $(n)$ \\
\hline 1. TP: direct instruction-clarify & 124 \\
2. SP: cohesive-name & 110 \\
3. SP: interactive-repeat or acknowledge & 68 \\
4. Attitude change: behavioral dissonance- & \\
instructor authenticity & 64 \\
5. Attitude change: cognitive dissonance-global & \\
context & 58 \\
6. SP: cohesive-greetings and salutations & 57 \\
7. Attitude change: behavioral dissonance-real & \\
world activism & 56 \\
8. TP: direct instruction-example & 55 \\
9. TP: facilitating discourse-summary & 45 \\
10. SP: interactive-approval & 41 \\
\hline
\end{tabular}

\section{Social Presence}

Research Question 1: How did a MOOC instructor establish SP to facilitate attitude change around the social issue of HT? 
The SP indicators consisted of affective, cohesive, and interactive codes (Table 3). Affective codes referred to the instructor's use of self-disclosure, personal values, emotion (e.g., the use of emoticons or expression of nonverbal emotions), enthusiasm, and humor. Cohesive codes included greetings, use of participant names, encouragement, group-references, and comments on collaboration and diversity. Interactive codes focused on acknowledgements, agreements and disagreements, approvals, and invitations for further discussion. Cohesive codes represented a clear majority of SP codes (47\%), and no affective category codes appeared in the top five SP codes; although, in total affective codes represented only a slightly lower percentage of total codes than interactive (Table 3).

Table 3

Instructor Social Presence Codes Distribution

\begin{tabular}{llll}
\hline Total SP Codes & No. (\%) affective codes & No. (\%) cohesive codes & $\begin{array}{l}\text { No. (\%) interactive } \\
\text { codes }\end{array}$ \\
\hline 541 & $135(25 \%)$ & $254(47 \%)$ & $152(28 \%)$ \\
\hline
\end{tabular}

Table 4

Top Five Instructor Social Presence Codes Observed

\begin{tabular}{lc}
\hline Code rank and name & Observations $(n)$ \\
\hline 1. Cohesive name & 110 \\
2. Interactive-repeat or acknowledge & 68 \\
3. Cohesive-greetings and salutations & 57 \\
4. Interactive-approval & 41 \\
5. Cohesive-group reference & 38 \\
\hline
\end{tabular}

The use of students' names had the highest frequency of SP indicators, and the acknowledgement of student efforts or ideas (repeat or acknowledge) was the second highest in frequency amongst codes. The third most common social indicator codes were greetings and salutations. Taken together, these indicate the instructor's strong desire to make efforts in creating a safe, open, and personal space for a meaningful global discussion on HT. The fourth most common indicator was the instructor posting approval of a student's comment, offering encouragement (approval). Finally, the instructor demonstrated attempts to establish a community of engaged (and potentially activist) learners by referencing the students as a group (group reference), which was the fifth most common SP indicator.

The interview data also indicated that a facilitation choice was made to address the issue of multiple perspectives and experiences. The instructor highlighted how important it was to her to facilitate the sharing of experiences, saying: 
So it is really, really important other people heard people say this is human trafficking in our country. I wanted them to talk to real people with real experiences because.... People are just so unemotional and so unconnected and so insensitive.

She further discussed how the creation of this community was an important component of spurring action:

If we connect these students together in a real personal kind of way. It would help to create that bond and that comfort and safety level to talk about real issues, involving something that's considered to be in some ways controversial and up for debate and discussion.

\section{Teaching Presence}

Research Question 2: How did a MOOC instructor establish teaching presence to facilitate attitude change around the social issue of HT?

TP is a well-established construct (Garrison et al., 2000, 2001), and several content analysis studies have provided indicators for the construct (Akyol, 2009; Anderson et al., 2001; Richardson et al., 2015). TP indicators were comprised of codes identifying the instructor facilitating discourse, providing direct instruction, and conducting assessment (Table 5). Facilitating discourse captured such activities as emphasizing, providing tips for succeeding in the course, summarizing, directing students' attention, and highlighting the instructor as a collaborator rather than a director. Direct instruction represented approaches such as providing examples or demonstrations, clarifying, or sharing resources. Assessment included the instructor providing formative and summative feedback for assignments or other course activities. Direct instruction represented the clear majority of codes, including $55 \%$ of the total TP codes and three of the top four TP codes (see Table 6).

Table 5

Instructor Teaching Presence Codes Distribution

\begin{tabular}{llll}
\hline Total TP codes & $\begin{array}{l}\text { No. (\%) facilitating } \\
\text { discourse codes }\end{array}$ & $\begin{array}{l}\text { No. (\%) direct } \\
\text { instruction codes }\end{array}$ & $\begin{array}{l}\text { No. (\%) assessment } \\
\text { codes }\end{array}$ \\
\hline 411 & $143(34.7 \%)$ & $224(54.5 \%)$ & $44(10.7 \%)$ \\
\hline
\end{tabular}

Thirty percent of the total TP codes indicated the instructor clarifying an aspect of the course. These included such items as course deadlines, assignment details, and so forth. Other frequent direct instruction activities were offering examples and providing resources. Providing summary was the only facilitating discourse activity in the top five, and giving formative assessment on the discussion was the only assessment activity in the top five.

Table 6 
Top Five Instructor Teaching Presence Codes Observed

\begin{tabular}{lc}
\hline Code rank and name & Observations $(n)$ \\
\hline 1. Direct instruction-clarify & 124 \\
2. Direct instruction-example & 55 \\
3. Facilitating discourse-summary & 45 \\
4. Direct instruction-resource & 28 \\
5. Assessment-formative discussion & 25 \\
\hline
\end{tabular}

The instructor found the discussion forums to be highly successful, noting, "The discussion platforms really worked. Any hour of the day I would go in, and I would see someone typing in something - two minutes ago, one minute ago." However, the process of going through so many discussion posts was a difficult task for which she was largely responsible. Other than some support from an instructional designer who helped moderate conflict within the forums, she was responsible for facilitating and responding in the forums. She found the process overwhelming and strongly described the strain it put on her.

I don't know how one person has time to go through and correct all of the factual, well, inaccurate opinions voiced in the class. So, as a facilitator, I thought, one, it's great that I've created this platform and people are being very independent for the most part and discussing things with each other, but then, at the same time, I felt like this is too much for one person to do.... We need to find a way to manage something with such good intent.

\section{Attitudinal Dissonance}

Research Question 3: How did a MOOC instructor establish cognitive, affective, and behavioral dissonance to facilitate attitude change around the social issue of HT?

The instructor also sought to facilitate attitude change in regards to HT through use of cognitive, affective, and behavioral dissonance. Use of dissonance for attitudinal change was the least common of the three code categories with 296 total codes, compared to 541 SP codes and 411 TP codes. Instructor strategies for promoting cognitive dissonance included such activities as readings and resources, instructor videos, discussing the global context of HT, and highlighting related social work. Affective codes focused on course activities such as personal stories shared in the course, discussing the provided undercover or documentary videos, and connecting to affective resources within the course. Behavioral dissonance codes represented discussions related to the PSA assignment, its application in the real world, real world activism, examples of the instructor living the message and being an authentic activist, connections to social media related to HT, and encouraging future collaboration in the fight against HT. A majority of codes represented attempts at creating behavioral dissonance (Table 7), encouraging students to take real world action, such as helping learners identify ways to publicly display their PSA projects in their local community. Behavioral dissonance codes were ranked in three of the top five dissonance codes (Table 8), with instructor authenticity and real world activism as frequent activities. 
Table 7

Instructor Dissonance Codes Distribution

\begin{tabular}{llll}
\hline Total dissonance codes & $\begin{array}{l}\text { No. (\%) cognitive } \\
\text { dissonance codes }\end{array}$ & $\begin{array}{l}\text { No. (\%) affective } \\
\text { dissonance codes }\end{array}$ & $\begin{array}{l}\text { No. (\%) behavioral } \\
\text { dissonance codes }\end{array}$ \\
\hline 296 & $93(31 \%)$ & $21(7 \%)$ & $182(61 \%)$ \\
\hline
\end{tabular}

Cognitive dissonance was represented in the top five with a focus on the global context of HT. Given the instructional design team's focus on the sharing of student stories and the creation of a community discussion around the topic, it appears that much of the instructor's cognitive dissonance instructional activities focused on highlighting the state of HT in various global contexts. The other cognitive dissonance activities in the top five were related to discussions around course readings and resources. Affective dissonance codes were by far the minority and were not represented in the top five.

Table 8

Top Five Instructor Dissonance Codes Observed

\begin{tabular}{lc}
\hline Code rank and name & Observations $(n)$ \\
\hline 1. Behavioral dissonance-instructor authenticity & 64 \\
2. Cognitive dissonance-global context & 58 \\
3. Behavioral dissonance-real world activism & 56 \\
4. Behavioral dissonance-PSA project & 31 \\
5.Cognitive dissonance-readings and resources & 22 \\
\hline
\end{tabular}

In the interview, the instructor noted the importance of making the students aware of the reality of HT, saying, "They need to know the facts.... It is not an exaggeration.... It is not some people around the world we shouldn't care about. They need to know that HT is real. It is awful; it is terrible; it is a violation of human rights."

Despite the goal of changing attitudes, she also noted that there is only so much an instructor and instructional designer can do. When discussing the challenge of managing a group of students in the course who were focused on the legal rights of sex workers and equated sex work with human trafficking, she conceded, "Someone who is trying to change attitudes as a facilitator, I have to ... consider the possibility that some attitudes cannot be changed; no matter what you design, it won't ever be changed."

\section{Discussion}


This study examined an instructor engaged in facilitating a MOOC focused on attitudinal change. By capturing all in-MOOC instructor posts during the course, we were able to provide a better understanding of the instructor's facilitation activities within a MOOC that used a philosophy of the instructor as a coparticipant. In other words, the instructional design choices of this MOOC deliberately limited the amount and length of instructor videos and instead focused on establishing a collaborative community of learners, differentiating itself with the more common xMOOC approaches to MOOC facilitation (Rodriguez, 2012).

Viewing this design and approach through the CoI lens, we can interpret how the instructor worked collaboratively with the students and instructional designer of the MOOC to support SP, TP, and attitudinal change in the course. Both facilitating discourse and assessment are TP activities that require careful reading of course discussions, while direct instruction is more of an instructor-led activity. In this MOOC, learners were largely responsible for providing assessment of each other's project work, and also of responding to each other's discussion posts. This is illustrative of how the role of online instructors need not reside solely within the confines of the traditional direct-instruction approach; indeed, a MOOC can be instructor-driven but not instructor-centered, ceding the focus on the instructor to a focus on the learning community at large.

Also, by examining instructor activities, we were able to highlight how this instructor sought to foster a welcoming and collaborative community focused on attitude change and promoting activism. We have illustrated a list of strategies utilized by this instructor to establish SP and TP with a goal towards fostering attitude change through the establishment of learner attitudinal dissonance (Kamradt \& Kamradt, 1999).

While there were frequent instructor activities aligned with demonstrating TP through clarifying, summarizing, and other direct-instruction approaches, we also saw her most common activities focused on SP. Whether utilizing strategies to promote course cohesion by greeting students, addressing them by name, or referencing the learning community as a whole, the instructor made frequent usage of strategies to promote the activist-oriented, community nature of the course. Interestingly, while her core goal was to change attitudes and push learners towards activism, her instructional role foremost focused on the establishment of the community, the facilitation of learning, and only then the creation of attitudinal dissonance.

However, much like TP was a shared component of the course, the intent of the instructional design relied on learner-shared stories to illustrate the reality of HT in varying global contexts and in doing so, facilitating attitudinal dissonance. This aligns with attitudinal change literature that notes how the establishment and effective facilitation of an environment promoting collaboration and critique can promote attitude change (Kamradt \& Kamradt, 1999; Simonson \& Maushak, 1996). Computer mediated communication has been shown to impact social influence broadly and attitude specifically (Sassenberg \& Jonas, 2007). Furthermore, the sense that one's attitude aligns with social consensus regarding a topic supports gaining confidence in new attitudes (Festinger, 1954; Visser \& Mirabile, 2004), an outcome that learners may gain through sharing of a targeted attitude in discussions. 
These instructor SP and TP activities revealed a different balance than those demonstrated by 12 instructors in a recent study of online courses (Richardson et al., 2015). In SP, this MOOC instructor was found to have $25 \%$ affective codes and $47 \%$ cohesive codes versus the recent study that found $36 \%$ for affective codes and 29\% for cohesive codes across 12 course instructors (Richardson et al., 2015). This may be an element of the MOOC instructor's teaching style or based on the nature of a large learner-base of a MOOC, but the shift in balance between the two categories of codes in the MOOC could be a gauge of how the instructor was highly focused on building group commitment through a shared intellectual task (Swan, Garrison, \& Richardson, 2009).

In TP, this MOOC instructor was found to have $34.7 \%$ facilitating discourse codes, $54.5 \%$ direct instruction codes, and $10.7 \%$ assessment codes versus the recent study that found $50 \%$ facilitating discourse codes, $31 \%$ direct instruction codes, and 19\% assessment codes across 12 course instructors by Richardson et al. (2015). Again, this may be the result of the MOOC instructor's teaching style or based on the nature of a large learner-base of a MOOC, but the increase in the use of direct instruction codes in the MOOC could be a measure of why MOOCs are becoming increasingly more popular. Direct instruction is defined as "the instructor provision of intellectual and scholarly leadership in part through the sharing of their subject matter knowledge with the students" (Swan et al., 2008), and this allows open access to that knowledge.

These instructor SP and TP activities also appeared to align with those suggested by Kilgore and Lowenthal (2015). In their study, Kilgore and Lowenthal explored methods for the humanization of MOOCs, using the CoI framework as a lens, and they found that SP could be established in a large offering such as a MOOC if "faculty and instructional designers take the time to design intentional learning experiences that help establish and maintain SP using a variety of technologies while they also actively engage learners and model effective ways to communicate throughout an entire course" (p. 382).

\section{Limitations and Future Research}

This study has a number of limitations. As it only examines a qualitative single case of an instructor, the results are not generalizable. Future case studies would allow comparison between instructional approaches and facilitation strategies to provide a clearer understanding of what strategies are most effective. In addition, because this study describes how an instructor established SP and TP while also fostering attitude change, the student perspective and learning outcomes are not examined. Future studies should examine the student perspectives to understand the differences perspectives on effective facilitation strategies.

This study explored an instructor's use of social presence, teaching presence, and attitudinal dissonance within a Human Trafficking MOOC, presenting an examination of instructor strategies in a MOOC designed to focus on the establishment of a collaborative learning community. The literature on the facilitation of MOOCs in general and for attitude change specifically is highly limited. This study provides insights into what strategies an instructor utilizes in this context and can provide insights to future instructional design and instruction of MOOCs in general and MOOCs for attitudinal change specifically. 
There is significant need for further research in these areas in order to improve MOOC instruction and to examine how open learning platforms can be leveraged to promote learning and impact learner attitudes. As MOOC offerings and enrollment continue to grow, understanding instructional design and facilitative approaches will improve the quality of MOOC learning experiences.

\section{References}

Akyol, Z. (2009). Examining teaching presence, social presence, cognitive presence, satisfaction and learning in online and blended course contexts (Unpublished doctoral dissertation). Middle East Technical University, Ankara, Turkey.

Anderson, T., Rourke, L., Garrison, R., \& Archer, W. (2001). Assessing teaching presence in a computer conferencing context. Journal of Asynchronous Learning Networks, 5(2). Retrieved from http://auspace.athabascau.ca/bitstream/2149/725/1/assessing teaching presence.pdf

Arbaugh, J. B. (2010). Sage, guide, both, or even more? An examination of instructor activity in online MBA courses. Computers \& Education, 55(3), 1234-1244. doi:10.1016/j.compedu.2010.05.020

Bangert, A. (2008). The influence of social presence and teaching presence on the quality of online critical inquiry. Journal of Computing in Higher Education, 2O(1), 34-61. doi:10.1007/BFo3033431

Bodenhausen, G. V., \& Gawronski, B. (2013). Attitude change. In D. Reisberg (Ed.), The Oxford handbook of cognitive psychology (pp. 957-969). New York, NY: Oxford University Press.

Carver, L., \& Harrison, L. M. (2013). MOOCs and democratic education. Liberal Education, 99(4). Retrieved from https://aacu.org/liberaleducation/2013/fall/carver-harrison

Clarà, M., \& Barberà, E. (2013). Learning online: Massive open online courses (MOOCs), connectivism, and cultural psychology. Distance Education, 34(1), 129-136. doi: 10.1080/01587919.2013.770428

Creswell, J. W. (2014). A concise introduction to mixed methods research. Thousand Oaks, CA: Sage.

Festinger, L. (1954). A theory of social comparison processes. Human Relations, 7, 117-140. doi: dx.doi.org/10.1177/001872675400700202

Flynn, J. (2013). MOOCS: Disruptive innovation and the future of higher education. Christian Education Journal, 1O(1), 149-162.

Gagne, R., Briggs, L. \& Wagner, W. (1992). Principles of instructional design. Belmont, CA: Wadsworth/Thomson Learning. 
Garrison, D. R. (2007). Online community of inquiry review: Social, cognitive, and teaching presence issues. Journal of Asynchronous Learning Networks, 11(1), 61-72. Retrieved from: http://sloanconsortium.org/sites/default/files/v11n1 8garrison.pdf

Garrison, D. R. (2011). E-Learning in the 21st century: A framework for research and practice (2nd ed.). London, UK: Routledge/Taylor and Francis.

Garrison, D. R. (2012). Article review: Social presence within the community of inquiry framework. The International Review of Research in Open and Distributed Learning, 13(1), 250-253. Retrieved from: http://www.irrodl.org/index.php/irrodl/article/view/1184/2099

Garrison, D. R., Anderson, T., \& Archer, W. (2000). Critical inquiry in a text-based environment: Computer conferencing in higher education model. The Internet and Higher Education, 2(2-3), 87-105. doi:10.1016/S1096-7516(00)00016-6

Garrison, D. R., Anderson, T. \& Archer, W. (2001). Critical thinking, cognitive presence, and computer conferencing in distance education. American Journal of Distance Education, 15(1), 7-23. doi: $\underline{10.1080 / 08923640109527071}$

Garrison, D.R. Cleveland-Innes, M. \& Fung, T. (2010). Exploring causal relationships among cognitive, social and teaching presence: Student perceptions of the Community of Inquiry framework. The Internet and Higher Education, 13(1-2), 31-36. doi:10.1016/j.iheduc.2009.10.002

Glaser, B. G. (1965). The constant comparative method of qualitative analysis. Social problems, 12(4), 436-445. dx.doi.org/10.2307/798843

Gunawardena, C.N. (1995). Social presence theory and implications for interaction and collaborative learning in computer conferences. International Journal of Educational Telecommunications, 1(2/3), 147-166. Retrieved from: http://www.editlib.org/p/15156/article 15156.pdf

Hostetter, C., \& Busch, M. (2006). Measuring up online: The relationship between social presence and student learning satisfaction. Journal of Scholarship of Teaching and Learning, 6(2), 1-12. Retrieved from: http://files.eric.ed.gov/fulltext/EJ854921.pdf

Hostetter, C., \& Busch, M. (2013). Community matters: Social presence and learning outcomes. Journal of the Scholarship of Teaching and Learning, 13(1), 77-86. Retrieved from: http://josotl.indiana.edu/article/view/3268/3623

Kamradt, T. F., \& Kamradt, E. J. (1999). Structured design for attitudinal instruction. In C. M. Reigeluth (Ed.), Instructional-design theories and models: A new paradigm of instructional theory (Vol. 2). Mahwah, NJ: Lawrence Erlbaum. 
Kanuka, H. (2011). Interaction and the online distance classroom: Do instructional methods effect the quality of interaction? Journal of Computing in Higher Education, 23, 143-156. doi: 10.1007/s12528-011-9049-4

Kilgore, W., \& Lowenthal, P. R. (2015). The human element MOOC: An experiment in social presence. In R. D. Wright (Ed.), Student-teacher interaction in online learning environments (pp. 373-391). Hershey, PA: IGI Global.

Kupczynski, L., Ice, P., Weisenmayer, R., \& McCluskey, F. (2010). Student perceptions of the relationship between indicators of teaching presence and success in online courses. Journal of Interactive Online Learning, 9(1), 23-43. Retrieved from: http://eric.ed.gov/?redir=http\%3a\%2f\%2fwww.ncolr.org\%2fjiol\%2fissues\%2fpdf\%2f9.1.2.pdf

Liyanagunawardena, T. R., Adams, A. A., \& Williams, S. A. (2013). MOOCs: A systematic study of the published literature 2008-2012. The International Review of Research in Open and Distributed Learning, 14(3), 202-227. Retrieved from: http://www.irrodl.org/index.php/irrodl/article/view/1455

Morris, T.A. (2011). Exploring community college student perceptions of online learning. International Journal of Instructional Technology \& Distance Learning, 8(6).

Mykota, D., \& Duncan, R. (2007). Learner characteristics as predictors of online social presence. Canadian Journal of Education, 30(1), 157-170. dx.doi.org/10.2307/20466630

Nagel, L., \& Kotze, T. (2010). Supersizing e-learning: What a CoI survey reveals about teaching presence in a large online class. Internet and Higher Education, 13, 45-51. doi:10.1016/j.iheduc.2009.12.001

Petrocelli, J. V., Tormala, Z. L., \& Rucker, D. D. (2007). Unpacking attitude certainty: Attitude clarity and attitude correctness. Journal of Personality and Social Psychology, 92(1), 30. dx.doi.org/10.1037/0022-3514.92.1.30

Picciano, A. G. (2002). Beyond student perceptions: Issues of interaction, presence, and performance in an online course. Journal of Asynchronous Learning Networks, 6(1), 21-40. Retrieved from: http://sloanconsortium.org/sites/default/files/v6n1 picciano 1.pdf

Richardson, J. C., Koehler, A., Besser, E., Caskurlu, S. Lim, J., \& Mueller, C. (2015). Conceptualizing and investigating instructor presence in online learning environments. International Review of Research in Open and Distributed Learning, 16(3), 256-297. Retrieved from: http://www.irrodl.org/index.php/irrodl/article/view/2123

Richardson, J. C., Swan, K. (2003). Examining social presence in online courses in relation to students' perceived learning and satisfaction. Journal of Asynchronous Learning Networks, 7(1), 68-88. Retrieved from: http://sloanconsortium.org/sites/default/files/v7n1 richardson 1.pdf 
Instructor's Use of Social Presence, Teaching Presence, and Attitudinal Dissonance: A Case Study of an Attitudinal Change MOOC Watson, Watson, Richardson, and Loizzo

Rodriguez, C. O. (2012). MOOCs and the AI-Stanford like courses: Two successful and distinct course formats for massive open online courses. European Journal of Open, Distance and E-Learning, 15(2). Retrieved from http://www.eurodl.org/?p=archives\&year=2012\&halfyear $=2 \&$ article $=516$

Ross, J., Sinclair, C., Knox, J., Bayne, S., \& Macleod, H. (2014). Teacher experiences and academic identity: The missing components of MOOC pedagogy. MERLOT Journal of Online Learning and Teaching, 1O(1), 56-68. Retrieved from: http://jolt.merlot.org/voliono1/ross 0314

Russo, T., \& S. Benson. (2005). Learning with invisible others: Perceptions of online presence and their relationship to cognitive and affective learning. Educational Technology \& Society, 8(1): 54-62. Retrieved from: http://www.jstor.org/stable/jeductechsoci.8.1.54

Sassenberg, K., \& Jonas, K.J. (2007). Attitude change and social influence on the net. In A.N. Joinson, K. Y. A. McKenna, T. Postmes, \& U. D. Reips (Eds.), Oxford handbook of internet psychology (pp. 273-288). Oxford, UK: Oxford University Press.

Shea, P., Li, C. S., \& Pickett, A. (2006). A study of teaching presence and student sense of learning community in fully online and web-enhanced college courses. The Internet and Higher Education, 9(3), 175-190. doi:10.1016/j.iheduc.2006.06.005

Simonson, M. R. (1979). Designing instruction for attitudinal outcomes. Journal of Instructional Development, 2(3), 15-19. doi:10.1007/BFo2984375

Simonson, M., \& Maushak, N. (1996). Instructional technology and attitude change. In D. H. Jonassen (Ed.), Handbook of research for educational communications and technology (pp. 984-1016). Mayway, NJ: Lawrence Erlbaum.

Swan, K., Garrison, D. R., \& Richardson, J. (2009). A constructivist approach to online learning: The Community of Inquiry framework. In C. R. Payne (Ed.), Information technology and constructivism in higher education: Progressive learning frameworks (pp. 43-57). Hershey, PA: IGI Global.

Swan, K., Matthews, D., Bogle, L., Boles, E., \& Day, S. (2012). Linking online course design and implementation to learning outcomes: A design experiment. The Internet and Higher Education, 15(2), 81-88. doi:10.1016/j.iheduc.2011.07.002

Swan, K., Shea, P., Richardson, J. C., Ice, P., Garrison, D. R., Cleveland-Innes, M., \& Arbaugh, J.B. (2008). Validating a measurement tool of presence in online communities of inquiry. E-mentor, 2(24), 1-12. Retrieved from: http://www.e-mentor.edu.pl/artykul/index/numer/24/id/543

$\mathrm{Tu}, \mathrm{C.}-\mathrm{H}$. (2002). The measurement of social presence in an online learning environment. International Journal on E-Learning, 1(2), 34-45. Retrieved from: http://www.editlib.org/p/10820/article 10820.pdf 
Visser, P. S., \& Mirabile, R. R. (2004). Attitudes in the social context: The impact of social network composition on individual-level attitude strength. Journal of Personality and Social Psychology, 87, 779-795. dx.doi.org/10.1037/0022-3514.87.6.779

Watson, W. R., Kim, W., \& Watson, S. L. (2016). Learning outcomes of a MOOC designed for attitudinal change: A case study of an Animal Behavior and Welfare MOOC. Computers \& Education, 96, 8393. doi:10.1016/j.compedu.2016.01.013

Wei, C.-W., Chen, N.-C., \& Kinshuk. (2012). A model for social presence in online classrooms. Educational Technology Research and Development, 6o(3), 529-545. doi: 10.1007/s11423-0129234-9

Zimbardo, P. G., \& Leippe, M. R. (1991). The psychology of attitude change and social influence. New York, NY: Mcgraw-Hill. 


\section{Appendix}

Categories

Indicators $(n)$

Social presence

Affective

Af-Sharing self disclosure

Af-Sharing values

Af-Sharing emotions

Af-Sharing enthusiasm

Af-Sharing humor

Cohesive

Co-Greeting \& salutations

Co-Using name

110

Co-Encouraging

Co-Using group reference

Co-Encouraging collaboration

Co-Encouraging diversity

Interactive

IN-Repeat/Acknowledgement

IN-Agreement/Disagreement

IN-Showing approval

IN-Extending invitation

Total social presence indicators

Teaching presence

Facilitating discourse

FD-Emphasizing

FD-Directing student attention

FD-Providing tips

FD-Summarizing

FD-Providing tips outside course

FD-Prompting

3

FD-Asking for clarification

FD-Connecting to content ideas

FD-Providing alternative viewpoint

Direct instruction

DI-Direct questioning

DI-Clarifying

DI-Providing examples

DI-Providing demonstration 
$\begin{array}{ll}\text { DI-Providing resources } & 28\end{array}$

Assessment 44

As-Formative feedback on discussion $\quad 25$

As-Summative feedback on discussion $\quad 11$

As-Formative feedback on other assignments 4

As-Summative feedback on other assignments 4

Total teaching presence indicators 411

Dissonance

$\begin{array}{ll}\text { Cognitive dissonance } & 93\end{array}$

CD-Discussing readings \& resources $\quad 22$

CD-Discussing instructor Videos $\quad 1$

CD-Discussing global context $\quad 58$

CD-Discussing social work practice $\quad 12$

Affective dissonance $\quad 21$

$\begin{array}{ll}\mathrm{AD}-\text { Discussing personal stories in course } & 18\end{array}$

$\mathrm{AD}-$ Discussing undercover or documentary videos 1

AD-Discussing affective Resources 2

Behavioral Dissonance $\quad 182$

BD-Discussing PSA project $\quad 31$

BD-Discussing PSA application to real world $\quad 15$

BD-Discussing real world activism $\quad 56$

BD-Discussing instructor authenticity and living message 64

BD-Discussing social media $\quad 5$

BD-Discussing future collaboration $\quad 11$

Total dissonance indicators 296

Total indicators 1248 